\title{
Determinación de los roles políticos, económicos-administrativo y de incidencia ejercidos por los diferentes actores desde las perspectivas de las políticas públicas en los territorios de comunidades negras
}

\section{Determination of political, economic-administrative and advocacy roles exercised by the different actors from the perspectives of the public policies in the territories of black communities}

\author{
Manuel Andrade*
}

\section{Resumen}

Con este artículo se pretende abordar a las comunidades negras frente a su autonomía y la descentralización en Colombia porque, de acuerdo con la Constitución, las entidades territoriales "gozan de autonomía para la gestión de sus intereses dentro de sus límites y la ley" con lo que queda claro el contenido de la autonomía de estos organismos según lo planteado. Se abordan los elementos esenciales y derechos fundamentales que recaen en ellas para ejercer su autonomía porque esta es una manifestación de la descentralización del país en sus diferentes dimensiones, en lo político y lo administrativo. Se analiza también el reconocimiento constitucional que se ha dado a las comunidades negras en el marco de la Ley 70 de 1993 y este reconocimiento constitucional y legal de los territorios de comunidades negras recayó sobre la figura de tierras baldias, lo cual contradice la concepción territorial integral de estas comunidades que trasciende a los territorios urbanos y al acceso por vía de ocupación ancestral.

Palabras clave: Constitución Nacional, Consejo comuntario, Modelo administrativo territorial para comunidades negras, Organizaciones étnicas territoriales.

\begin{abstract}
This article aims to address the black communities facing their autonomy and decentralization in Colombia, according to the constitution, territorial entities "enjoy autonomy for the management of their interests within their limits and the law" with what remains the autonomy of these bodies as. It addresses the essential elements and fundamental rights that fall into them to exercise their autonomy since this is a manifestation of the de-
\end{abstract}

* Economista, Magister en Administración, Magister en Gobierno y Políticas Públicas. Jefe de Control Interno, Instituto de Investigaciones Ambientales del Pacífico (IIAP), Quibdó, Colombia. e-mail: mandrade@iiap.org.co 


\section{Bioetnia Volumen 13, 2016}

centralization of the country in its different dimensions, in the political and administrative is also analyzed the constitutional recognition that has given a black communities in the framework of Law 70 of 1993 and this constitutional and legal recognition of the territories of black communities fell on the figure of uncultivated lands, which contradicts the integral territorial conception of these communities that transcends urban territories and access by means of ancestral occupation.

Keywords: Community council, National Constitution, Territorial administrative model for communities black, Territorial ethnic organizations.

\section{Introducción}

En Colombia en 1991 se promulgó una nueva Constitución Política en la que se reconoció el carácter pluriétnico y multicultural de la nación. Esto implicó el diseño y la adopción de nuevos marcos jurídicos para superar la discriminación y la histórica exclusión a la que se habían visto sometidos los afrodescendientes colombianos. Uno de estos instrumentos jurídicos fue la Ley 70 de 1993 (se debe citar en la lista de ref.) o Ley de Comunidades Negras, con la cual se realizó la titulación colectiva de sus territorios. La Ley 70 también significó un nuevo ejercicio de participación política, pues al reconocer al pueblo negro como etnia se le garantizaba un lugar de privilegio en su interlocución con el Estado a partir de la creación de los consejos comunitarios como máxima autoridad al interior de los territorios titulados.

Esto produce la necesidad de políticas públicas claras que garanticen a estas organizaciones jugar un verdadero rol de funcionamiento administrativo pues siguen presentando falencias, carecen de un modelo de gestión administrativa que fortalezca su autonomía territorial y les de independencia económica porque el reconocimiento es solo de funcionalidad, pues no cuentan entre sus entes territoriales del Estado, lo que las deja sin competencias importantes en el ejercicio de su autonomía y con dependencia económica de otros entes territoriales.

Las comunidades negras frente a la autonomía y descentralización en Colombia. De acuerdo con la Constitución, las entidades territoriales "gozan de autonomía para la gestión de sus intereses dentro de sus límites y la ley" con lo que queda claro el contenido de la autonomía (el Artículo 287 lo plantea). En ese sentido, para sus ejercicios las entidades territoriales deben gobernarse por autoridades propias, ejercer las competencias que les correspondan, administrar los recursos, establecer los tributos necesarios para el cumplimiento de sus funciones y participar de las rentas nacionales.

Los anteriores son los elementos o derechos fundamentales para ejercer autonomía porque son manifestaciones de la descentralización del país en sus diferentes dimensiones: en lo político (autoridades elegidas popularmente), lo fiscal (recursos propios y transferidos del nivel nacional) y en lo administrativo (competencias). Queda claro y de acuerdo con la opinión de líderes de organizaciones como Cocomacia, Cocomopoca, Acaba, Riscales, Asocasan y Delfines, que las organizaciones negras y sus consejos comunitarios (CC) carecen de estos elementos y de estas dimensiones al menos en lo que tiene que ver con los aspectos políticos y fiscales, pues aunque se les asigna autonomía esta se limita únicamente en algunos aspectos de tipo administrativo territorial.

Reconocimiento constitucional dado a las comunidades negras en el marco de la Ley 70 de 1993. El reconocimiento constitucional y legal de los territorios de comunidades negras (CONE) recayó sobre la figura de tierras baldías, lo cual contradice la concepción territorial integral de estas comunidades que trasciende a los territorios urbanos y al acceso por vía de ocupación ancestral, imposibilitando la titulación colectiva urbana y la titulación de otras áreas necesarias para recrear cultura; la existencia de territorios rurales 
y territorios urbanos advierte muchas situaciones complejas en la falta de definición de funciones y competencias de los diferentes actores presentes en el territorio.

Las organizaciones étnicas territoriales (OET) de comunidades negras han sido objeto de la agregación de responsabilidades, derivadas de los desarrollos normativos que han tenido lugar especialmente a partir de la expedición de la Constitución de 1991. Estos cambios repercuten en las condiciones con las que ejercen su autonomía, por ejemplo, limitando la libertad de sus acciones bien sea en el ejercicio de una competencia, en la disponibilidad de recursos o en la capacidad de decidir el destino de dichos recursos y, lo más importante, en su no reconocimiento en el marco de la Constitución como órganos descentralizados.

Lo anterior se debe a la marcada diferencia que establece la Corte Constitucional colombiana entre los dos conceptos "la autonomía y la descentralización que entrecruzan sus mecanismos de acción en múltiples aspectos" y responden a ópticas distintas. Mientras la descentralización busca mayor libertad de las instancias periféricas territoriales y funcionales en la toma de decisiones para mayor eficiencia en el manejo de la cosa pública, la autonomía encauza sus propósitos hacia la mayor libertad de los miembros asociados con una comunidad en aras de un mayor bienestar y mejor control de sus propios intereses (Sentencia C-478-92).

En Colombia se introdujo la descentralización y la autonomía territorial con el fin de romper las tendencias centralistas imperantes durante la vigencia de la Constitución de 1886 y de forma más precisa antes de la expedición de las normas que condujeron a la descentralización de la década de 1980; las autoridades territoriales eran nombradas por el ejecutivo del nivel inmediatamente superior lo que configuraba una estricta jerarquía entre los gobernantes de los diferentes niveles del Estado, de tal forma que las decisiones y quienes las tomaban no consultaban las necesidades y preferencias de sus beneficiarios, generando brechas entre los impactos reales y los deseados, evidenciando la incapacidad del Estado para dar respuestas adecuadas a las necesidades y problemáticas sociales; el proceso de descentralización permitió trasladar al nivel territorial los elementos que se consideraron necesarios para hacer posible que la gestión pública se orientara al mejoramiento de las condiciones de vida de las personas.

Estas modificaciones implicó la transformación de una clase de Estado a otra, debido a los fenómenos de descentralización y autonomía, se intentó transitar hacia un Estado eficiente y efectivo pasando de un estado unitario centralizado a otro descentralizado, y de un marco normativo que le daba prevalencia a lo nacional a otro donde cobra relevancia lo territorial, tal como quedó consignado en el Artículo 1 de la Constitución: "Colombia es un Estado social de derecho, organizado en forma de República unitaria, descentralizada, con autonomía de sus entidades territoriales". Sin embargo, tanto la descentralización como la autonomía son fenómenos inherentes al ámbito territorial que fundamentan su esencia en la existencia del Estado unitario.

Dicho contenido reducto, descrito en el Artículo 287 de la Constitución debe siempre ser respetado por el legislador (Sentencia C-004 de 1993), ya que de esta forma se garantiza la capacidad de autogobierno y autogestión (Sentencia C-600A-95); es decir, se garantiza la capacidad de las entidades territoriales para autodeterminarse y gobernarse por órganos propios en forma independiente y sin injerencia del poder central en lo interno mediante la utilización del conjunto de competencias que les han sido asignadas para el cumplimiento de los cometidos que le son propios (Sentencia C-126-93). Sin embargo, más que quedar en manos del Estado a nivel territorial, la autonomía se encuentra ligada a la soberanía popular y a la democracia participativa, pues se requiere una participación permanente que permita que la decisión ciudadana se exprese sobre 


\section{Bioetnia Volumen 13, 2016}

cuáles son las necesidades a satisfacer y la forma de hacerlo.

$\therefore$ Actores que definen el MATOCONE como una política pública para las organizaciones de comunidades negras? ¿Y el papel de la comunidad y/o de la organización social en esa definición? Para dar una aplicación de políticas públicas al Modelo Administrativo Territorial de Organizaciones de Comunidades Negras (MATOCONE), este debe ser asociado con los asuntos del gobierno y con los sistemas políticos como actividades de las instituciones del Estado, generadas o procesadas en el marco de los procedimientos de instituciones y organizaciones gubernamentales. Por tanto los actores que lo definen son: El Estado como organización política, social e independiente del territorio colombiano. El poder que reside en el gobierno porque a través de este el estado controla, administra y dirige por medio de sus instituciones, en el entendimiento de que ejercen una autoridad legítima y que, mediante las decisiones que toman protegen y dirigen la comunidad, la organización social que sirve de base a la ideología predominante, y las organizaciones étnicas a través de sus consejos comunitarios como dueños ancestrales del territorio.

Se diferencian dos categorías de actores en manera general para la aplicabilidad del MATOCONE: los sociales y los políticos, apoyándonos en los actores sociales como unidades reales de acción en la sociedad, pues son los tomadores y ejecutores de decisiones que inciden en la realidad social de la cual forman parte, actúan como individuos o colectivos, sometidos a ciertas condiciones culturales, étnico, políticas y territoriales; se consolidan de forma que si el Estado es permeable a la opinión social, garantizan mayor transparencia a las actuaciones gubernamentales, al tiempo que incrementa la confianza de la ciudadanía, y los actores políticos que reproducen su poder en relación a los otros actores y en referencia al gobierno, son unidades abiertas que pueden ser penetradas por la sociedad, sin la cual no sobre- vivirían. Tal es el caso de políticos que sin los votos o sin el apoyo de ciertos grupos dejarían de serlo, de hecho se requiere de una política pública clara que garantice a las organizaciones étnicas desempeñar su verdadero rol de funcionamiento administrativo al interior de sus territorios; una política pública para un modelo de gestión administrativa que fortalezca su autonomía territorial con independencia económica y una política pública que reconozca a las organizaciones étnicas como entes territoriales para garantizar no solo su funcionalidad y competencias en el ejercicio de su autonomía, sino también su independencia económica de otros entes territoriales.

Por lo que la decisión del MATOCONE como alternativa planteada, tiene una alta influencia de determinación, primero en el poder político, los cuales y lo más probable es que no van a tener, ni mostrarán voluntad para elevarlo a políticas públicas que dé una posible solución a los problemas que se presentan al interior de las organizaciones de comunidades negras, porque son los más interesados en que estas organizaciones no tengan independencia administrativa, económica $\mathrm{y}$ territorial en el manejo de su territorio.

Segundo en el poder alcanzado por técnicos y algunos líderes de proceso organizativo quienes podrían influir de alguna manera en dicha determinación; sin embargo, se deja de manifiesto que este proceso se podría ver afectado y no hacerse efectivo por los intereses personales infiltrados en la mayoría de ellos porque su posición es actuar de punto medio entre el poder público y las comunidades; y por último, en las comunidad representados en sus organizaciones étnicas y sus consejos comunitarios las cuales en término de poder están nulas pero siempre están proponiendo alternativas de solución para su accionar pero sin ser escuchadas o tenidas en cuenta la calificación.

La indiferencia del Estado y los diferentes intereses que se presentan en el manejo interno del territorio por los distintos actores que están inmersos en su proceso de implementación que podría 
dificultar la implementación del MATOCONE como política pública para estas comunidades.

\section{Conclusiones}

Los procesos administrativos de las organizaciones étnicas en el marco de las políticas públicas se deben plantear a partir de la formulación de sus planes de etnodesarrollo y sus planes de vida, que deben responder a la necesidad y el fortalecimiento de su autonomía, su cohesión y auto-identificación entre otros. Este se debe construir con prácticas de participaciones políticas, económicas y sociales basadas en los principios comunitarios desde lo que se es, se tiene, se sabe y se hace.

Se observó que en la actualidad el desarrollo de estas comunidades no están orientando de manera adecuada con proyectos de armonización y progreso que redunden en el bienestar social de las comunidades y de su territorio y que aunque se tienen tópicos de los requerimientos comunitarios, no se ha definido una ruta que demarque el cumplimiento de sus objetivos, haciendo que se requiera urgentemente el rediseño de un modelo en cuyo accionar se involucren todos los líderes comunitarios, los políticos, alcaldes y concejales de los territorios afrocolombianos para asumir su liderazgo y replantear estrategias económicas con modelos administrativos propios y sirvan de impulso al crecimiento y al desarrollo económico y social de las comunidades étnicas.

Cabe anotar que por los procesos que se vienen desarrollando al interior de las comunidades negras (en el marco de la Ley 70 de 1993), el diseño y aplicación de un modelo administrativo como herramienta de política pública, cobra gran importancia porque involucra intereses comunes en dinámicas de crecimiento y desarrollo ya que en él se ven representados los distintos actores, que vienen inmerso en el proceso. Por tanto, hay que generar una serie de acciones que involucren en sus procedimientos la consecución de los ob- jetivos propuesto desde el MATOCONE, en todo los aspectos territoriales, culturales, políticos, sociales, de autonomía e independencia económica.

La aplicación del MATOCONE como política pública cumple con las características del empoderamiento (Compromiso, Conocimiento y Convicción), por lo que los directivos comunitarios tendrían que asumir un rol que permita el cambio y transformación en los territorios colectivos en cuanto a su capacidad administrativa, comprendiendo e interpretando la administración moderna para garantizar la permanencia, la mejora continua y la sostenibilidad económica en el tiempo, de todas ellas a través de sus consejos comunitarios, en los territorios con titulación colectiva y ajustándolos de manera independiente a los cambios políticos y administrativos que se puedan presentar en el estado en un momento determinado.

De otro lado la normatividad del estado colombiano sigue evolucionandoy presentando cambios continuos en sus estructura, por tanto, cuando se plantea el MATOCONE como una herramienta de política pública y de marco referencial para la administración territorial, es porque cuenta con todos los componentes teóricos, administrativos, jurídicos y tienen su aplicación en el contexto territorial para el que fue diseñado, con las normas de la función administrativa pública de Colombia y con los aportes empíricos de los líderes comunitarios.

Sin embargo, la implementación del MATOCONE como política pública depende mucho de la voluntad social que tengan las organizaciones en hacerlo y del papel que juegue la dirigencia política para llevar a cabo este proceso, sumando además algunos factores limitantes que giran alrededor del recurso humano, como su disciplina, su liderazgo social y otros estándares de desempeño que tenga la organización, en términos de calidad, credibilidad, cobertura y satisfacción comunitaria. 


\section{Bioetnia Volumen 13, 2016}

\section{Recomendaciones}

Es importante ahondar en el estudio y análisis de modelos administrativos diseñados para las organizaciones étnicas y para esto se debe hacerun trabajo arduo de socialización y divulgación con las comunidades, con políticos de las diferentes zonas, representantes legales y juntas directivas de los consejos comunitarios para adoptarlo y que sea reconocido, aceptado y apropiado, como una herramienta de manejo administrativo donde se demarque claramente las competencias que tienen las organizaciones de comunidades negras y la de los distintos entes territoriales del estado colombiano al interior del territorio.

Se deben diseñar las estrategias necesarias para que estos modelos sean elevados a política pública porque serían una herramienta fundamental dada la necesidad del reconocimiento de la autonomía e independencia económica que requieren los grupos étnicos en aspectos territoriales, ambientales, culturales, políticos y jurídicos, y por la búsqueda de la igualdad en el manejo de temas administrativos que garanticen las mismas oportunidades de crecimiento y desarrollo a los entes territoriales en Colombia.

Se deben adelantar más estudios sobre la gestión administrativa territorial comunitaria con líderes y miembros de juntas directivas al interior de los consejos comunitarios y cabildos indígenas; porque con su holística, su lógica, su ambiente, cultura y cosmovisión pueden fortalecer los modelos administrativos existentes en la actualidad en Colombia.

Hay que hacer una revisión al tema de la autonomía comunitaria pues debe ser profundizado desde lo aspectos constitucionales, hasta el ejercicio mismo de las organizaciones étnicas, ya sean, determinando claramente los elementos que la constituyen y el alcance real que tienen al interior de sus territorios.

Es importante que se adopten modelos administrativos étnicos de tal manera que se convierta en una herramienta de política pública porque los entes territoriales del estado y las organizaciones de comunidades negras se deben involucrar en un modelo que conjuntamente jalone el desarrollo de la región y este sea el reflejo de los planes de desarrollo de los entes y los planes de etnodesarrollo planteados desde los consejos comunitarios.

\section{Literatura citada}

Congreso de Colombia. Ley $\mathrm{N}^{\circ} 70$ de 1993. Por la cual se desarrolla el artículo transitorio 55 de la Constitución Politica. URL disponible en: http://www.alcaldiabogota.gov.co/sisjur/normas/Norma1.jsp?i=7388

Corte Constitucional. República de Colombia. Sentencia $\mathrm{N}^{\circ} \mathrm{C}-478-92$. Control de constitucionalidad/tránsito constitucional. URL disponible en: http://www.corteconstitucional.gov.co/relatoria/1992/C-478-92.htm

Corte Constitucional. República de Colombia. Sentencia C-004 de 1993. Unidad Normativa. URL disponible en: http://www.corteconstitucional.gov.co/relatoria/2003/C-004-03.htm

Corte Constitucional. República de Colombia. Sentencia C-600A-95. Reserva de ley orgánica. URL disponible en: http://www.corteconstitucional.gov.co/relatoria/1995/C-600A-95.htm

Corte Constitucional. República de Colombia. Sentencia C-126-93. Estado unitario/Entidades territoriales/ Descentralización administrativa/Autonomía. URL disponible en: http://www.corteconstitucional.gov.co/ relatoria/1993/c-126-93.htm 